\title{
RAQUITISMO EN CERDOS EN CRECIMIENTO
}

Rickets in growing pigs

\section{Pallarés F.J. ${ }^{1}$, Gómez S. ${ }^{1}$, Sánchez-Uribe P. ${ }^{2}$, López-Asensio M.J. ${ }^{3}$}

${ }^{1}$ Departamento de Anatomía y Anatomía Patológica Comparadas, Facultad de Veterinaria, Universidad de Murcia. ${ }^{2}$ Servicio Técnico de Porcino, Elanco Animal Health. ${ }^{3}$ Servicios Veterinarios Intega S.L.

* Autor para correspondencia: Francisco J. Pallarés, Histología y Anatomía Patológica, Facultad de Veterinaria, Universidad de Murcia, Campus de Espinardo, 30071 Murcia, España. Tel: +34 868884336, Fax: +34 868884147, e-mail: pallares@um.es

Historial del artículo:

Recibido: 17 noviembre 2012

Aceptado: 7 enero 2013

\section{RESUMEN}

Se describe la aparición de un proceso de raquitismo en cerdos en crecimiento. Los signos clínicos fueron cojeras, fracturas óseas y paraplejía. En la necropsia se apreció engrosamiento de las zonas próximas a la articulación tibiotarsal y las articulaciones costocondrales. Microscópicamente se observó engrosamiento del periostio con presencia de focos de osificación, líneas de osificación irregular y la aparición de lagunas de cartílago entre el tejido osificado. El análisis del pienso demostró que casi la totalidad del fósforo presente procedía de las materias primas, por lo que no se había añadido ninguna cantidad en el corrector vitamínico-mineral. El diagnóstico final fue de raquitismo asociado a un desequilibrio mineral, determinándose que estaba relacionado con un fallo durante la fabricación del pienso, ya que se había adicionando una décima parte del corrector que figuraba en la fórmula.

Palabras clave: raquitismo, cerdo, fósforo, vitamina D, calcio, desequilibrio mineral.

\section{ABSTRACT}

The appearance of a process of rickets in growing pigs is described. The clinical signs observed were lameness, bone fractures and paraplegia. The necropsy revealed thickening of the tibiotarsal and costocondral joints. Microscopically, thickening of the periostium with presence of ossification foci, irregular ossification lines and 
the appearance of cartilage areas between the ossified tissue was observed. Feed samples were analyzed and was demonstrated that almost the total phosphorum present came from the raw materials and no phosphorum was added in the vitamin-mineral complex. The final diagnosis was rickets due to a mineral imbalance. The problem was due to a error in manufacturing feed. Ten fold less quantity of vitamin-mineral complex of the specified was added to the feed by a transciption error in the formula.

Key words: rickets, pig, phosphorus, vitamin D, calcium, mineral imbalance.

Las osteodistrofias son enfermedades metabólicas que implican una osificación deficiente. Dentro de ellas se incluye el raquitismo, que afecta a los animales en crecimiento, y que se caracteriza por una mineralización insuficiente del hueso, con acumulación de osteoide y engrosamiento de las placas de crecimiento, por fallo de la osificación endocondral (Liu, 2002; Carlson y Weisbrode, 2012; Madson et al., 2012). Las principales causas del raquitismo son la suplementación inadecuada de vitamina $\mathrm{D}_{3}$ en la dieta, una absorción disminuida de fósforo por aporte inferior al recomendado, una relación calcio:fósforo incorrecta en el pienso y un aporte inadecuado de calcio en el alimento (Madson et al., 2012). Las proporciones de calcio:fósforo en la dieta deben seguir las recomendaciones acordes a la edad del animal (FEDNA, 2006).

Las enfermedades metabólicas son raras en los sistemas actuales de producción porcina debido al control en la fabricación del pienso para cada edad y tipo de animal. En este caso clínico describimos la aparición de un proceso de raquitismo en lechones en transición en una granja comercial del sureste español.

El caso tuvo lugar en una granja de 4000 cerdas que produce lechones de $20 \mathrm{~kg}$. Un grupo de 1240 lechones, con un peso medio de 21 $\mathrm{kg}$, procedentes de esta granja fue trasladado a una nave de cebo situada a $3 \mathrm{~km}$ de distancia. La nave de cebo tenía cuadras con capacidad para 14 lechones con un $30 \%$ de superficie sólida y el resto de rejilla de hormigón.

El día después del traslado aparecieron 35 animales con cojera, la mayoría de la pata trasera derecha, y dos animales con parálisis del tercio posterior debido a fractura de la columna vertebral. El personal encargado de las descargas informó que ningún animal presentó cojera, retraso o problemas de marcha en la granja de origen. El veterinario excluyó el maltrato de los animales durante la descarga y prescribió un tratamiento con antiinflamatorios no esteroideos, obteniendo una respuesta positiva. A la semana de su llegada a la nave de cebo, los lechones fueron vacunados frente a la enfermedad de Aujeszky, incrementándose al día siguiente el número de animales con cojera.

Dos días más tarde se detectaron cojeras en 20 animales, algunos de ellos con paraplejía, en un grupo de lechones de otra granja de la misma empresa. Circunstancia que se fue repitiendo, durante las tres semanas siguientes, en los animales procedentes de todas las granjas de origen de la empresa, incrementándose con el movimiento forzado de los animales, como en las vacunaciones. En algunos casos el porcentaje de animales afectados fue del $5 \%$.

En todos los casos los animales presentaban malos aplomos, con rotación de las extremidades y abultamientos duros al tacto, no móviles, en las inserciones tendinosas de los músculos de las extremidades.

Dadas las manifestaciones clínicas se plantearon dos hipótesis sobre su etiología: a) una infección estreptocócica, que fue descartada por tener lugar en diferentes granjas de origen y de forma simultánea, y b) un problema de debilidad ósea asociado a un déficit nutricional de calcio, fósforo o de ambos, y que predisponía a los lechones a lesiones articulares y fracturas por esfuerzo, por lo que se tomaron muestras del pienso de transición para su aná- 


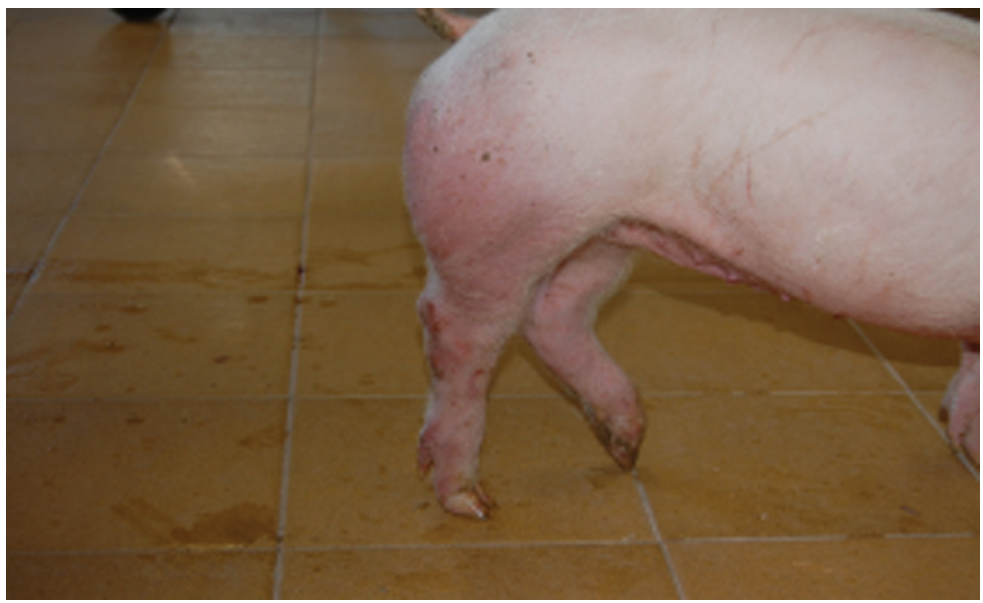

Figura 1. Cerdo afectado que apoya con la punta de la pezuña.

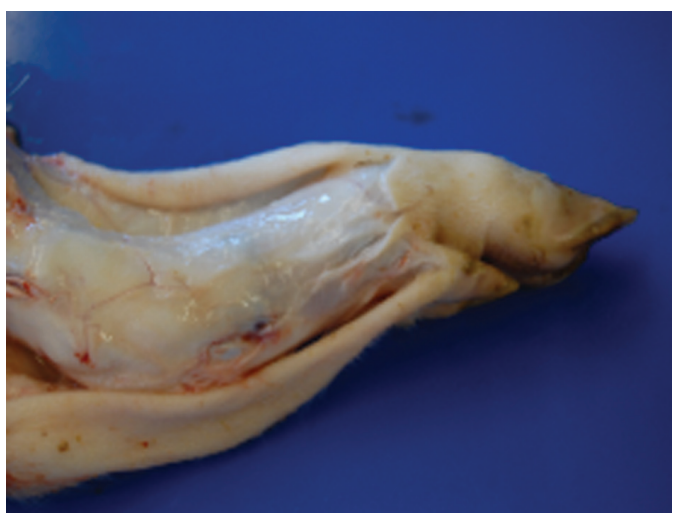

Figura 2. Abultamiento en la zona tarsal.

lisis. Adicionalmente, se enviaron dos animales afectados para su estudio anatomopatológico. Estos animales presentaban envaramiento, apoyo con la punta de la pezuña (Figura 1) y dificultad para caminar. Macroscópicamente, el tarso estaba engrosado en la zona próxima a la articulación tibiotarsal (Figura 2), así como las articulaciones costocondrales (Figura 3).

Microscópicamente se observó un engrosamiento del periostio del tarso y de la articulación costocondral debido a un aumento del tejido conectivo. En algunas zonas de las costillas el periostio aparecía engrosado, con tejido

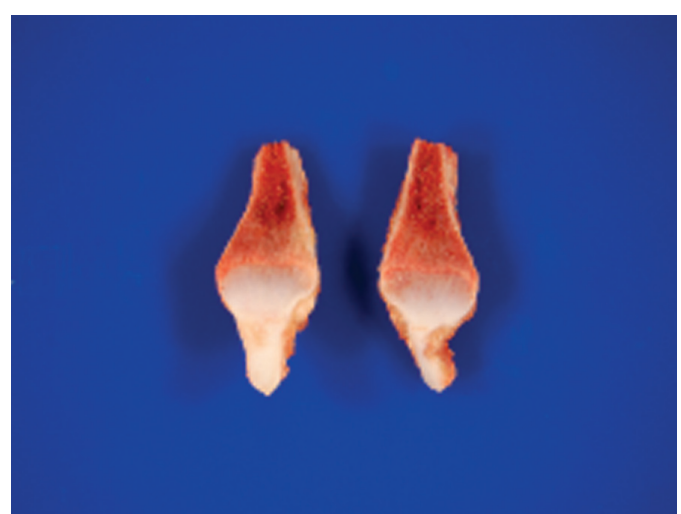

Figura 3. Abultamiento en la unión costocondral.

conectivo inmaduro subyacente, focos de osificación (Figura 4) y línea de osificación irregular. Las muestras del tarso presentaban lagunas de cartílago entre el tejido osificado (Figura 5) y mieloesclerosis, por lo que el diagnóstico final fue de osteodistrofia.

El pienso de transición fue analizado mediante la determinación simultánea de proteína, calcio y fósforo utilizando el autoanalizador de flujo continuo AA3 (Axflow), observando que la casi la totalidad del fósforo presente en el pienso procedía de las materias primas (Tabla $1)$. 


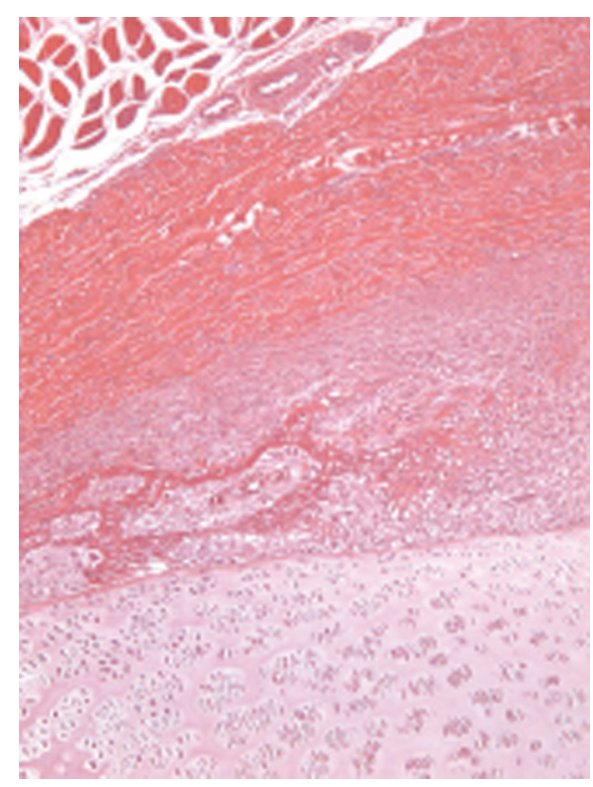

Figura 4. Engrosamiento del periostio con focos de osificación y tejido conectivo inmaduro bajo el mismo.

Tabla 1. Niveles de calcio y fósforo en las muestras de pienso analizadas

\begin{tabular}{|l|c|}
\hline \multicolumn{2}{|c|}{ MUESTRA 1 } \\
\hline Calcio & $0,51 \%$ \\
\hline Fósforo & $0,38 \%$ \\
\hline \multicolumn{2}{|c|}{ MUESTRA 2 } \\
\hline Calcio & $0,41 \%$ \\
\hline Fósforo & $0,34 \%$ \\
\hline \multicolumn{2}{|c|}{ MUESTRA 3 } \\
\hline Calcio & $0,79 \%$ \\
\hline Fósforo & $0,35 \%$ \\
\hline
\end{tabular}

Dados los resultados del estudio del cuadro lesional y de las analíticas del pienso, se estableció un diagnóstico final de osteodistrofia asociada a un desequilibrio mineral (raquitismo), por lo que los animales fueron tratados con inyecciones intramusculares de $5 \mathrm{ml} \mathrm{de}$ vitamina $\mathrm{A}_{1} \mathrm{D}_{3}$ y $\mathrm{E}$, y $10 \mathrm{ml}$ de borogluconato cálcico durante 4 días. Asimismo, se administró

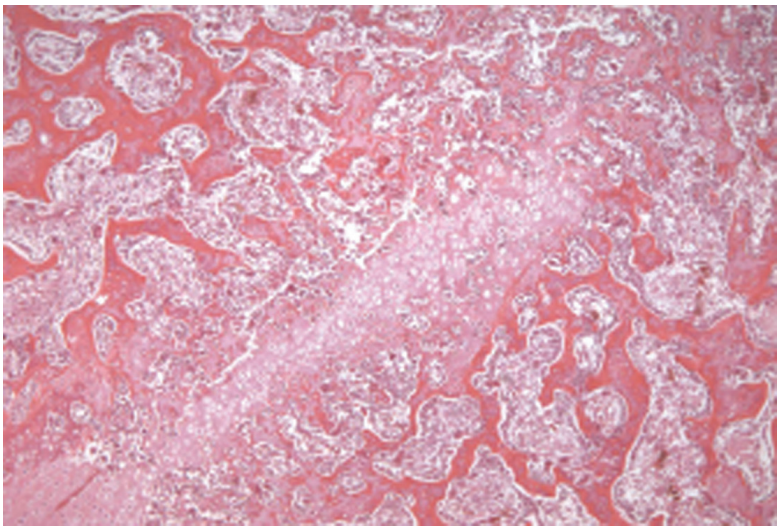

Figura 5. Lagunas de cartílago entre el tejido osificado del tarso.

un antiinflamatorio no esteroideo (ketoprofeno) a una dosis de $1 \mathrm{ml} / 20 \mathrm{~kg}$ de peso vivo durante 3 días, que mejoró la sintomatología de los animales afectados. También se aumentó el confort de las cuadras con abundante serrín en las zonas de descanso.

Establecida la posible etiología de un fallo nutricional, se revisó el proceso de fabricación desde la llegada de las materias primas hasta la salida del producto final, determinándose que, debido a un error en la transcripción de la fórmula de transición, no se estaba suministrando la cantidad recomendada del corrector vitamínico-mineral.

Una vez detectado y subsanado el error no aparecieron más animales afectados en ninguna de las granjas de la empresa. Los animales afectados fueron reubicados en lazaretos, donde se mantuvieron aquellos que mostraron evidencias de mejoría hasta alcanzar el peso de matadero, mientras que los muy afectados fueron sacrificados.

Las dietas actuales en el ganado porcino de crecimiento-cebo van dirigidas a potenciar el crecimiento de la masa muscular y tienen menos en cuenta la formación del hueso, por lo que variaciones cualitativas y cuantitativas de algunos nutrientes pueden generar un problema óseo clínico o subclínico (Maxson y Ma- 
han, 1983; Madson et al., 2012). La mayoría de casos de raquitismo en las explotaciones ganaderas tienen lugar cuando los ingredientes del pienso no se han mezclado adecuadamente o están en cantidades deficientes (Thomson, 2007). En el presente caso, aunque la fórmula era correcta, se estaba adicionando tan solo la décima parte del corrector vitamínico mineral.

Las lesiones macro y microscópicas observadas son similares a las descritas en casos de raquitismo en cerdos (Madson et al., 2012), aunque en nuestro caso no se detectaron los signos de tetania, temblores y muertes súbitas descritas por estos autores. Estos signos plantean el diagnóstico diferencial con infecciones del sistema nervioso central como la estreptococia, descartada en nuestro caso por el estudio histopatológico.

La confirmación del proceso de raquitismo, además de la clínica y las lesiones, requiere la medición de los niveles séricos de calcio, fósforo, fosfatasa alcalina, creatín quinasa $\mathrm{y}$ $25(\mathrm{OH}) \mathrm{D}_{3}$, producto de la hidroxilación de la vitamina D en el hígado (Madson et al., 2012). En los casos de raquitismo por deficiencia de fósforo o vitamina $\mathrm{D}$, su concentración sérica aparecerá disminuida, mientras que las concentraciones de fosfatasa alcalina y creatín quinasa suelen aparecer aumentadas en esta enfermedad, la primera por un incremento en la actividad osteoclástica y la segunda debido a una alteración muscular debido a postración prolongada del animal o por hipocalcemia. Otras pruebas laboratoriales que pueden ayudar a confirmar el diagnóstico son la medición del ratio calcio:fosforo en orina (Hagemoser et al., 2000) o la medición del porcentaje de cenizas en hueso (Budde y Crenshaw, 2003; Hastad et al., 2004).

En nuestro caso pudimos disponer de los valores de calcio y fósforo del pienso que consumían los cerdos durante ese periodo y donde se pudo comprobar que casi la totalidad del fósforo procedía de las materias primas y no del corrector, lo que junto con el cuadro ana- tomoclínico determinó el diagnóstico final de raquitismo asociado a un desequilibrio mineral.

\section{BIBLIOGRAFÍA}

BUDDE R.A., CRENSHAW T.D. 2003. Chronic metabolic acid load induced by changes in dietary electrolyte balance increased chloride retention but did not compromise bone in growing swine. J. Anim. Sci. 81: 197-208.

CARLSON C.S., WEISBRODE S.E. 2012. Bones, joints, tendons, and ligaments. En: Pathologic basis of veterinary disease. Eds. McGavin M.D., Zachary J.F., 5 ${ }^{\text {a }}$ Edición. Elsevier Mosby, St. Louis, Estados Unidos. pp. 920-971.

FUNDACIÓN ESPAÑOLA PARA EL DESARROLLO DE LA NUTRICIÓN ANIMAL (FEDNA). 2006. Necesidades nutricionales para el ganado porcino: normas FEDNA. http://www.fundacionfedna.org/normas_ fedna_formulacion_piensos.pp: 60 .

HAGEMOSER W.A., GOFF J.P., SANDERSON T.P., HAYNES J.S. 2000. Osteopenic disease in growing pigs: diagnostic methods using serum and urine calcium and phosphorus values, parathormone assay, and bone analysis. J. Vet. Diagn. Invest. 12: 525-534. HASTAD C.W., DRITZ S.S., TOKACH M.D., GOODBAND R.D., NELSSEN J.L., DEROUCHEY J.M., BOYD R.D., JOHNSTON M.E. 2004. Phosphorus requirements of growing-finishing pigs reared in a commercial environment. J. Anim. Sci. 82: 2945-2952.

LIU S.K. 2002. Metabolic diseases in animals. Semin. Musculoskelet. Radiol. 6: 341-346.

MADSON D.M., ENSLEY S.M., GAUGER P.C., SCHWARTZ K.J., STEVENSON G.W., COOPER V.L., JANKEB.H., BURROUGH E.R., GOFF J.P., HORST R.L. 2012. Rickets: case series and diagnostic review of hipovitaminosis $\mathrm{d}$ in swine. J. Vet. Diagn. Invest. 24: 1137-1144. 
MAXSON P.F., MAHAN D.C. 1983. Dietary calcium and phosphorus levels for growing swine from 18 to 57 kilograms body weight. J. Anim. Sci. 56: 1124-1134.
THOMSON K. 2007. Bones and joints. En: Pathology of Domestic Animals. Ed: Maxxie M.G., 5 $5^{\text {a }}$ Edición. Elservier, Philadelpia, Estados Unidos. pp. 1-184. 